\title{
AVALIAÇÃO DA VIABILIDADE TÉCNICA E ECONÔMICA DA UTILIZAÇÃO DE BIOMASSAS COMO FONTE ENERGÉTICA ALTERNATIVA EM FORNOS INDUSTRIAIS ${ }^{1}$
}

\author{
Lílian Maluf de Lima \\ Ana Maria Kefalás Oliveira ${ }^{3}$ \\ Paulo de Tarso Carletti Filho ${ }^{4}$ \\ Renata Cristina Ferrari ${ }^{5}$ \\ José Vicente Caixeta Filho
}

Resumo: Este trabalho foi realizado ao longo do ano de 2003, dentro do ambiente de uma grande indústria localizada no Estado de São Paulo e que possuía sua matriz energética predominantemente focada no coque de petróleo, um produto que, após sua queima, implica alta emissão de gases $\left(\mathrm{CO}_{\text {e }} \mathrm{CO}_{2}\right)$ na atmosfera e que é relativamente caro, se comparado a uma série de biomassas. Devido à localização geográfica favorável dessa indústria, foram observadas grandes ofertas de biomassas que poderiam ser consideradas como alternativas de combustível para seus fornos industriais. Diversas biomassas foram analisadas, e o bagaço de cana-de-açúcar e os resíduos de madeira (serragem e cavaco) foram considerados os mais indicadas para a indústria em questão.

Palavras-chave: biomassa, energia, transporte e otimização.

Recebido em 05/10/2005 Aceito em 31/01/2006.

2 Aluna de Doutorado em Economia Aplicada da ESALQ/USP. E-mail: lmlima@esalq.usp.br Endereço: Rua Elvira Boyes, 355, Jd. Petrópolis, Piracicaba/SP. CEP: 13420-670 Telefone: (19) 3429-8824

3 Mestre em Ciências. Área de concentração: Economia Aplicada - ESALQ/USP.

E-mail: anakefalas@yahoo.com.br - Endereço: Av. Pádua Dias, 11, Piracicaba/SP. CEP: 13418-900 Telefone: (11) 8556-7337

4 Mestre em Ciências. Área de concentração: Economia Aplicada - ESALQ/USP. E-mail: paulo carletti@yahoo.com.br - Endereço: Av. Pádua Dias, 11, Piracicaba/SP. CEP: 13418-900 Telefone: (11) 8432-2552

5 Mestranda em Economia Aplicada pela ESALQ/USP. E-mail: rtferrari@yahoo.com.br - Endereço: Av. Pádua Dias, 11, Piracicaba/SP. CEP: 13418-900 Telefone: (19) 8139-6504

6 Professor Titular do Departamento de Economia, Administração e Sociologia da ESALQ/USP.

E-mail: jvcaixet@esalq.usp.br - Endereço: Departamento de Economia, Administração e Sociologia - LESESALQ/USP. Av. Pádua Dias, 11, Piracicaba/SP. CEP: 13418-900 Telefone: (19) 3417-8736 


\section{Introdução}

A busca de fontes alternativas de energia sempre foi foco de discussões tanto no meio acadêmico quanto no empresarial. Ao longo da década de 90, tal temática recebeu especial atenção da sociedade, principalmente devido a questionamentos acerca da preservação do meio ambiente. Ressaltam-se, aqui, acordos de preservação ambiental; normas de qualidade que visam ao meio ambiente, como a ISO 14000; o protocolo de Kyoto; e até a criação de diversos cursos de graduação e pósgraduação em universidades.

$\mathrm{Na}$ área de energia, o que vem sendo feito, nos últimos tempos, é a busca de fontes alternativas de energia, principalmente renováveis, em detrimento das não-renováveis, como o petróleo. Assim, o uso de resíduos agroindustriais recebeu destaque em pesquisas e aplicações de cunho industrial, cenário no qual se inclui o uso de biomassas como fonte renovável de energia (Glossário, 2003).

Este trabalho foi realizado ao longo do ano de 2003, dentro do ambiente de uma grande indústria localizada no Estado de São Paulo e que possuía sua matriz energética predominantemente focada no coque de petróleo, um produto que, após sua queima, implica alta emissão de gases $(\mathrm{CO}$ e $\mathrm{CO}_{2}$ ) na atmosfera e que é relativamente caro, se comparado a uma série de biomassas. Devido à localização geográfica favorável dessa indústria, foram observadas grandes ofertas de biomassas que poderiam ser consideradas alternativas de combustível para os seus fornos industriais.

\section{Metodologia}

Na realização deste trabalho quatro atividades-macro foram especificadas: a primeira se relaciona com o levantamento de fontes de biomassa, a partir da busca exaustiva na literatura existente e por meio de visitas a agentes de mercado relacionado com oferta ou demanda de alguma 
biomassa mais específica; a segunda, com a classificação das fontes de energia; a terceira, com a avaliação técnico-econômica das biomassas selecionadas; por fim, foi elaborada a ferramenta gerencial, que incorpora modelo matemático de programação linear para facilitar a atualização dos dados das biomassas e para auxiliar as tomadas de decisão acerca da utilização de biomassas.

\section{Principais resultados observados}

\subsection{Levantamento de fontes de biomassa}

Para essa atividade, realizaram-se buscas exaustivas de literatura existente, em bibliotecas especializadas, dissertações, teses, artigos, jornais e internet. Tais documentos, 197 no total, foram classificados a partir dos seguintes relacionadores: "Aplicações e experiências", "Estatísticas", "Legislação", "Teoria e Definições" e "Outros". Cada documento também foi devidamente sumarizado, e tais resumos foram disponibilizados, ao longo do estudo, a todos os membros da equipe.

Em seguida, foi realizada a leitura completa de documentos selecionados a partir de uma lista prévia de biomassas, na qual foram incluídos madeira, cana-de-açúcar, briquetes, biodiesel, resíduos industriais (bagaço de laranja, café, licor-negro e embalagens Tetra-Pak), biogás, resíduos de arroz, carvão vegetal, resíduos agrícolas e bambu. Cada uma dessas biomassas foi especificada e estudada, a fim de se obter uma prévia dos problemas a serem enfrentados nas fases seguintes do estudo.

Nesse sentido, foram agendadas e realizadas visitas a 11 empresas que utilizavam biomassa como fonte de energia interna no processo industrial ou que poderiam ser potenciais fornecedoras de biomassa. Tomou-se também como referência a "área de influência" da indústria, conforme ilustrado na Figura 1. 


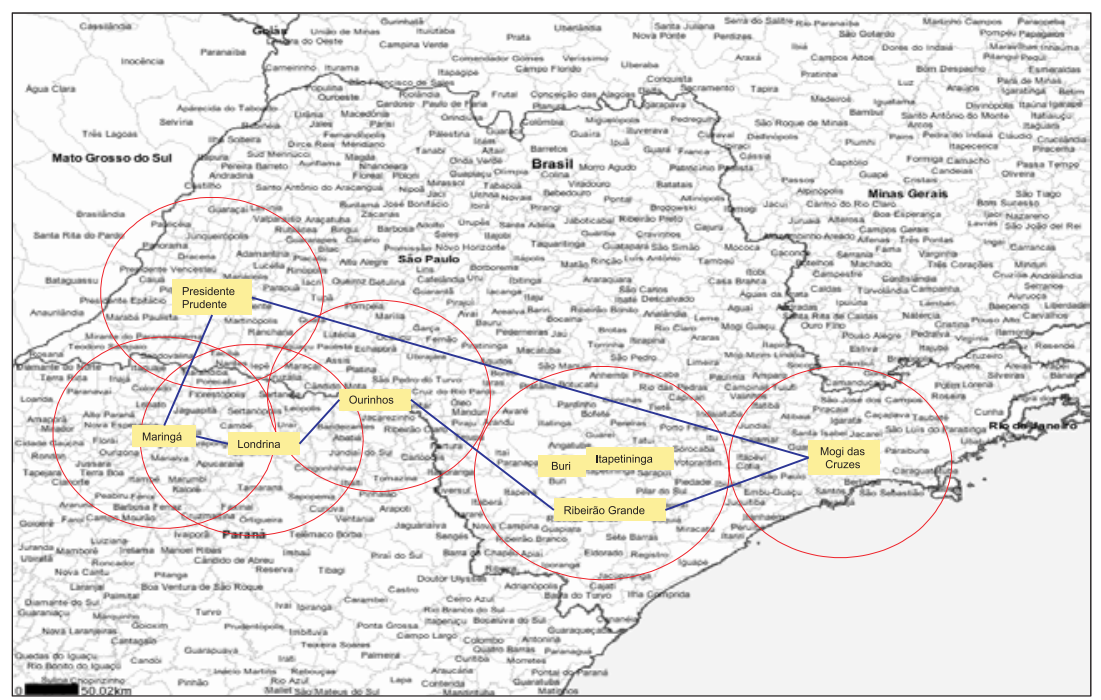

Figura 1 - Áreas de influência consideradas na análise de oferta de biomassas.

Fonte: Dados da pesquisa.

\subsection{Classificação das fontes de energia}

$\mathrm{Na}$ segunda fase, foram aplicados critérios de seleção às biomassas originalmente consideradas e, em razão das pesquisas e visitas realizadas, foram excluídas as seguintes biomassas: biogás, licor negro e resíduos de cervejaria.

O biogás foi excluído devido à não existência de uma infra-estrutura de captação desse combustível nos aterros sanitários municipais e o licor negro, devido à constatação de que a maioria das empresas de papel e celulose reaproveita esse produto - em um ciclo de recuperação química - para reutilização na extração da celulose. Além disso, identificou-se quantidade muito pequena de informações na literatura sobre a queima desse resíduo em empresas que não sejam do ramo de papel e celulose. 
A falta de referências bibliográficas relacionadas com experiências de queima de resíduos de cervejaria para geração de energia, somada à confirmação, em visita à empresa, de que esses são vendidos para alimentação animal, contribuiu também para a exclusão dessa biomassa.

Assim, foram consideradas nas análises subseqüentes as seguintes biomassas: Bagaço de Cana, Biodiesel (Óleo de Fritura), Briquetes Comerciais (aparas de madeira), Briquetes Comerciais (casca de arroz), Briquetes Comerciais (madeira de lei), Briquetes Comerciais (serragem), Briquetes Comerciais Gerais, Casca de Arroz, Embalagens Tetra-Pak, Farelo de Polpa Cítrica, Gás Natural, Lixo Urbano, Resíduos de Café, Resíduos de Madeira (Cavaco) e Resíduos de Madeira (Serragem).

A cada uma dessas biomassas foram atribuídas notas de 1 a 5 (1 indesejável; 2 - pouco desejável; 3 - desejável; 4 - muito desejável; 5 altamente desejável), para uma série de critérios relacionados com:

\section{- Custo}

Qual o custo em $\mathrm{R} \$ / \mathrm{Gcal}$ ?

Quanto menor o custo, maior a nota.

\section{- PCI}

Qual o PCI (Poder Calorífico Inferior) em kcal $/ \mathrm{kg}$ ?

Quanto mais alto o valor do PCI, maior será a nota.

\section{- Teor de cinzas}

Qual o teor de cinzas em porcentagem?

Quanto menor o teor de cinzas, maior será a nota.

\section{- Densidade}

Qual a densidade $\mathrm{em} \mathrm{kg} / \mathrm{m}^{3}$ ?

Quanto maior a densidade, maior será a nota.

\section{- Umidade}

Qual a umidade média em porcentagem?

Quanto menor a umidade, maior será a nota. 


\section{- Nível de emissão de gases}

Quais os gases emitidos na queima da biomassa?

Quanto menor o nível de gases do efeito estufa emitido, maior será a nota.

\section{- Necessidade de pré-processamento}

Há necessidade de pré-processamento da biomassa para a queima na caldeira?

Se não houver, maior será a nota atribuída.

\section{- Experiência de uso}

Há experiência de queima da biomassa em caldeiras?

Se houver, maior a nota.

\section{- Uso concorrente para geração de energia}

Há concorrência de uso da biomassa para geração de energia?

Se não houver, maior será a nota.

- Disponibilidade na área de influência

Qual a disponibilidade da biomassa, em Gcal, na área de influência da empresa?

Quanto maior a disponibilidade na área, maior será a nota.

\section{- Armazenagem}

Há necessidade de uma estrutura específica para o armazenamento da biomassa?

Se não houver, maior será a nota.

\section{- Sazonalidade}

Há sazonalidade na oferta da biomassa?

Se não houver, maior será a nota.

\section{- Licenciamento}

A empresa possui licenciamento dos organismos ambientais (Cetesb, por exemplo) para a queima de cada fonte de biomassa?

Se sim, maior será a nota atribuída.

\section{- Legislação}

Qual o nível de "burocracia" legal 1 păra a queima de cada biomassa?

Se o nível de burocracia for baixo, maior será a nota atribuída. 
Lilian Maluf de Lima, Ana Maria Kefalás Oliveira, Paulo de Tarso Carletti Filho,

Renata Cristina Ferrari \& José Vicente Caixeta Filho

\section{- Literatura encontrada}

Qual a quantidade de artigos encontrados sobre cada biomassa?

Se a quantidade for alta, maior será a nota atribuída.

O sumário, com as escalas de notas adotadas para cada um dos critérios, é apresentado no Quadro 1.

Quadro 1-Escala de notas para os critérios de seleção de biomassas

\begin{tabular}{|l|c|c|c|c|c|}
\hline \multicolumn{2}{|c|}{ Critérios } & \multicolumn{4}{c|}{ Nota } \\
\hline Custo (R\$/Gcal) & $\mathbf{1}$ & $\mathbf{2}$ & $\mathbf{3}$ & $\mathbf{4}$ & $\mathbf{5}$ \\
\hline PCI (kcal/kg) & {$[24, \ldots)$} & {$[18,24)$} & {$[12,18)$} & {$[6,12)$} & {$[0,6)$} \\
\hline Teor de cinzas (\%) & {$[0,1.500)$} & {$[1.500,4.000)$} & {$[4.000,7.000)$} & {$[7.000,10.000)$} & {$[10.000, \ldots)$} \\
\hline Densidade (kg/m3) & 8 ou mais & $6 \mathrm{a} 8$ & $4 \mathrm{a} 6$ & $2 \mathrm{a} 4$ & $0 \mathrm{a} 2$ \\
\hline Umidade média (\%) & {$[0,200)$} & {$[200,400)$} & {$[400,700)$} & {$[700,1.000)$} & {$[1.000, \ldots)$} \\
\hline Nível de emissão de gases & {$[40, \ldots)$} & {$[30,40)$} & {$[20,30)$} & {$[10,20)$} & {$[0,10)$} \\
\hline Necessidade de pré-processamento & & & & & \\
\hline Experiência de uso & Sim & & & & Não \\
\hline Uso concorrente para geração de energia & Nenhuma & & Alguma & & Muita \\
\hline Disponibilidade na área de influência (Gcal) & Muito & & Algum & & Pouco \\
\hline Armazenagem (investimento em infra-estrutura) & Pouco & & Médio & & Muito \\
\hline Sazonalidade de produção & Alto & & Médio & & Nenhum \\
\hline Licenciamento & Sim & & & & Não \\
\hline Legislação (nível de burocracia) & Sim & & & & Não \\
\hline Literatura encontrada (quantidade) & Alta & & Média & & Baixa \\
\hline
\end{tabular}

Fonte: Dados da pesquisa.

Os limites superior e inferior de cada uma das escalas foram obtidos a partir de estudos e levantamentos realizados nas empresas visitadas e na indústria. Além disso, quando pertinente, tomou-se como referência o coque de petróleo (por exemplo, no item "custo", o valor máximo que uma biomassa poderia vir a ter seria igual ao valor praticado na época para aquisição do coque de petróleo). O critério "nível de emissão de gases" não foi utilizado, dada a dificuldade de obtenção deste dado.

Os Quadros 2 e 3 trazem, para cada biomassa, os dados obtidos e as respectivas notas atribuídas. Os dados dos Quadros 2 e 3 foram então retrabalhados, a partir da especificação de três cenários que consideraram, de maneira distinta, o grau de importância de cada nota atribuída a cada biomassa. 
REVISTA DE ECONOMIA E AGRONEGÓCIO, VOL.4, $N^{\circ} 1$

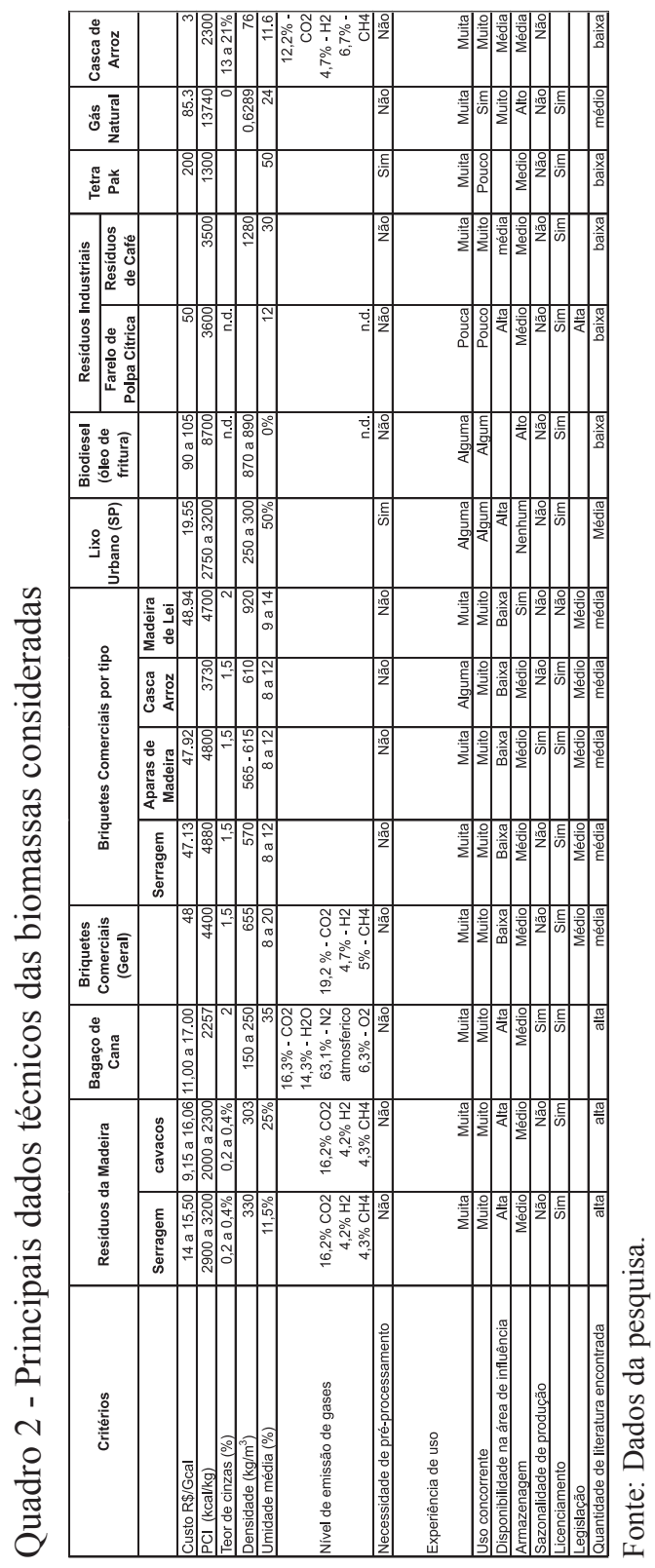


Lílian Maluf de Lima, Ana Maria Kefalás Oliveira, Paulo de Tarso Carletti Filho, Renata Cristina Ferrari \& José Vicente Caixeta Filho

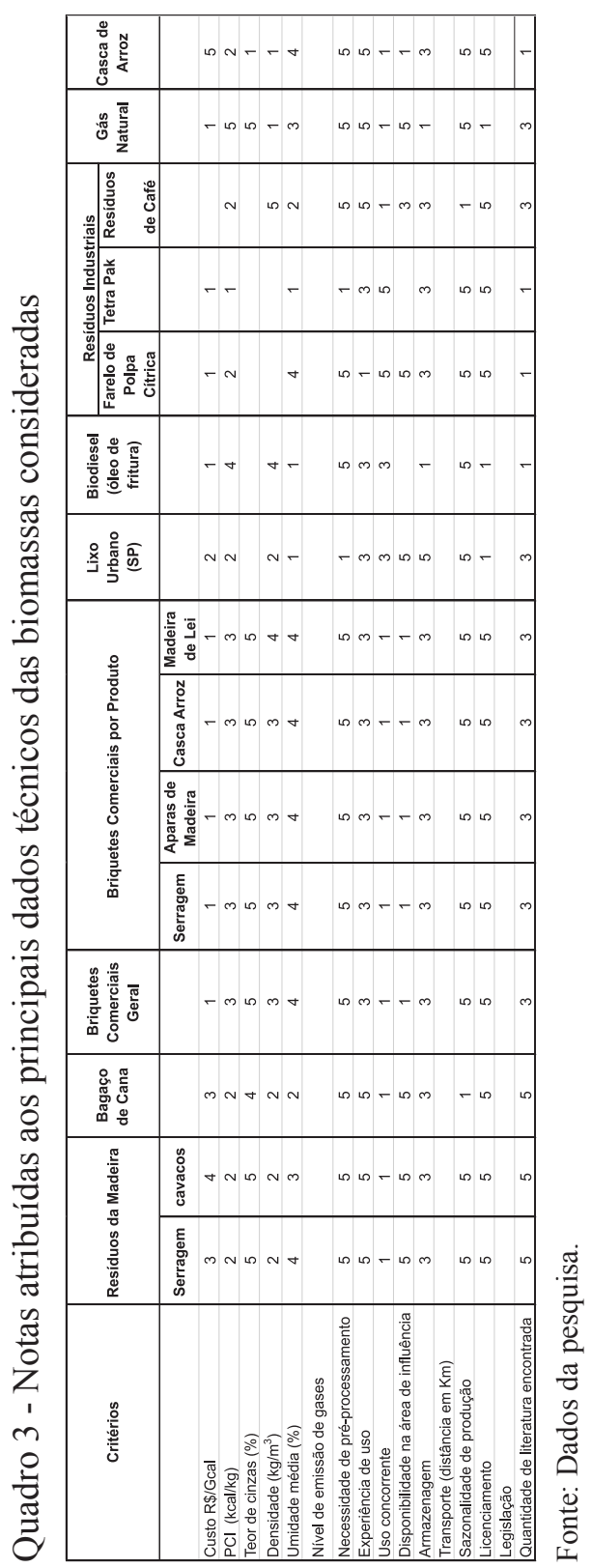


Assim, no primeiro cenário foram atribuídos pesos iguais a todos os critérios (Quadro 4); no segundo, foram aplicados pesos distintos a cada critério (Quadro 5); no terceiro e no último cenário, distinguiu-se apenas a influência do critério "custo" (Quadro 6).

Quadro 4 - Ponderações adotadas para o Cenário 1

\begin{tabular}{|l|c|}
\hline \multicolumn{1}{|c|}{ Critérios } & Ponderação \\
\hline Custo R\$/Gcal & 1 \\
PCI (kcal/kg) & 1 \\
Teor de Cinzas (\%) & 1 \\
Densidade $\left(\mathrm{kg} / \mathrm{m}^{3}\right.$ ) & 1 \\
Umidade Média (\%) & 1 \\
Nível de Emissão de Gases & 1 \\
Necessidade de Pré-processamento & 1 \\
Experiência de Uso & 1 \\
Uso Concorrente & 1 \\
Disponibilidade na Área de Influência & 1 \\
Armazenagem & 1 \\
Transporte (distância em km) & 1 \\
Sazonalidade de Produção & 1 \\
Licenciamento & 1 \\
Legislação & 1 \\
Quantidade de Literatura Encontrada & 1 \\
\hline
\end{tabular}

Fonte: Dados da pesquisa. 
Lilian Maluf de Lima, Ana Maria Kefalás Oliveira, Paulo de Tarso Carletti Filho, Renata Cristina Ferrari \& José Vicente Caixeta Filho

Quadro 5 - Ponderações adotadas para o Cenário 2

\begin{tabular}{|l|c|}
\hline \multicolumn{1}{|c|}{ Critérios } & Ponderação \\
Custo R\$/Gcal & 5 \\
PCI (kcal/kg) & 4 \\
Teor de Cinzas (\%) & 2 \\
Densidade $\left(\mathrm{kg} / \mathrm{m}^{3}\right)$ & 4 \\
Umidade Média (\%) & 3 \\
Nível de Emissão de Gases & 3 \\
Necessidade de Pré-processamento & 2 \\
Experiência de Uso & 2 \\
Uso Concorrente & 4 \\
Disponibilidade na Área de Influência & 5 \\
Armazenagem & 2 \\
Transporte (distância em km) & 4 \\
Sazonalidade de Produção & 2 \\
Licenciamento & 4 \\
Legislação & 3 \\
Quantidade de Literatura Encontrada & 1 \\
\hline
\end{tabular}

Fonte: Dados da pesquisa. 
Quadro 6 - Ponderações adotadas para o Cenário 3

\begin{tabular}{|l|c|}
\hline \multicolumn{1}{|c|}{ Critérios } & Ponderação \\
Custo R $\$ / \mathrm{Gcal}$ & 5 \\
PCI $(\mathrm{kcal} / \mathrm{kg})$ & 1 \\
Teor de Cinzas $(\%)$ & 1 \\
Densidade $\left(\mathrm{kg} / \mathrm{m}^{3}\right)$ & 1 \\
Umidade Média $(\%)$ & 1 \\
Nível de Emissão de Gases & 1 \\
Necessidade de Pré-processamento & 1 \\
Experiência de Uso & 1 \\
Uso Concorrente & 1 \\
Disponibilidade na Área de Influência & 1 \\
Armazenagem & 1 \\
Transporte (distância em km) & 1 \\
Sazonalidade de Produção & 1 \\
Licenciamento & 1 \\
Legislação & 1 \\
Quantidade de Literatura Encontrada & 1 \\
\hline
\end{tabular}

Fonte: Dados da pesquisa.

A classificação final das biomassas foi obtida da média aritmética dos ordenamentos de cada uma das biomassas, nos três cenários especificados. Os resultados foram organizados em três categorias (A, B e C), aos moldes de uma curva ABC tradicional (Ballou, 2001). O Quadro 7 traz um sumário desses resultados. 
Lílian Maluf de Lima, Ana Maria Kefalás Oliveira, Paulo de Tarso Carletti Filho, Renata Cristina Ferrari \& José Vicente Caixeta Filho

Quadro 7 - Média final dos três cenários especificados e classificação das biomassas

\begin{tabular}{|c|l|c|c|c|c|}
\cline { 2 - 5 } \multicolumn{1}{|c|}{ Biomassa } & Cenário1 & Cenário2 & Cenário3 & Média \\
\hline 1 & Resíduos de Madeira (cavaco) & 2 & 1 & 1 & 1,33 \\
\hline 2 & Resíduos de Madeira (serragem) & 1 & 2 & 2 & 1,67 \\
\hline 3 & Bagaço de Cana & 4 & 4 & 4 & 4,00 \\
\hline 4 & Farelo de Polpa Cítrica & 3 & 3 & 7 & 4,33 \\
\hline 5 & Briquetes Comerciais (madeira de lei) & 5 & 6 & 6 & 5,67 \\
\hline 6 & Resíduos de Café & 10 & 5 & 5 & 6,67 \\
\hline 7 & Casca de Arroz & 12 & 7 & 3 & 7,33 \\
\hline 8 & Briquetes Comerciais Gerais & 6 & 9 & 8 & 7,67 \\
\hline 9 & Briquetes Comerciais (serragem) & 7 & 10 & 9 & 8,67 \\
\hline 10 & Briquetes Comerciais (aparas de madeira) & 8 & 11 & 10 & 9,67 \\
\hline 11 & Gás Natural & 11 & 8 & 12 & 10,33 \\
\hline 12 & Briquetes Comerciais (casca de arroz) & 9 & 12 & 11 & 10,67 \\
\hline 13 & Lixo Urbano & 14 & 14 & 13 & 13,67 \\
\hline 14 & Biodiesel (óleo de fritura) & 13 & 13 & 14 & 13,33 \\
\hline 15 & Embalagens Tetra-Pak & 15 & 15 & 15 & 15,00 \\
\hline
\end{tabular}

Fonte: Dados da pesquisa.

As análises demonstraram, empiricamente, um resultado que vinha se concretizando ao longo das pesquisas, das visitas e dos trabalhos realizados pela equipe.

As altas ofertas de madeira e bagaço de cana-de-açúcar na região (Estados de São Paulo e Paraná, principalmente) indicavam o uso dessas biomassas. Esse fator, somado ao fator custo, foi o principal norteador da classificação. Entretanto, há biomassas que foram classificadas como potenciais, mas, devido a fatores específicos, não são indicadas para uso de queima em caldeira. Nesse contexto destacam-se a casca de café, a casca de arroz, o lixo urbano, o farelo de polpa de laranja, as embalagens "tetra-pak", o óleo de fritura e a casca de café, que são descritas e caracterizadas a seguir.

A casca de café é altamente utilizada na geração de energia na secagem do café, principalmente nas fazendas de produção do sul de Minas Gerais, estado que possui, aproximadamente, $47 \%$ da produção nacional do produto. No entanto, a casca, o maior potencial energético do café, é 
retirada no momento do beneficiamento, que é realizado após colheita e secagem dos grãos. É nesse processo que se encontra a dificuldade maior, qual seja, a coleta da casca no local de beneficiamento e secagem, o que torna difícil sua utilização. Infelizmente, a existência de um canal de centralização de coleta de cascas de café é desconhecida no mercado; além disso, por ser um resíduo agrícola, os próprios produtores reutilizamno como adubo orgânico.

Por sua vez, a casca de arroz apresenta expressivo potencial para geração de energia, e sua utilização já é intensa na região Sul do país. Cerca de $50 \%$ da produção nacional está concentrada nessa região, onde estão localizadas diversas indústrias de cimento e de geração de energia elétrica, as quais utilizam esse produto em suas matrizes energéticas. No entanto, o principal problema para o uso na Indústria Cimento Ribeirão é a disponibilidade da biomassa para queima, que é caracterizada pela baixa oferta no Estado de São Paulo, que não atende à sua demanda em energia. Esse fator já pode ser considerado como suficiente para não se apreciar tal biomassa como prospectiva fonte energética; em contrapartida, sua maior vantagem é o baixo custo.

Com relação ao lixo urbano, observou-se, por meio da pesquisa realizada, que há uma série de estudos em curso sobre a viabilidade de sua utilização na geração de energia. Entretanto, a burocracia vigente para se utilizar o lixo pode ser considerada fator limitante, uma vez que há necessidade de contatar prefeituras municipais, assim como de obter alvará para utilizálo. Cabe destacar que as estruturas, nos aterros sanitários, ainda são muito precárias e abrigam famílias que se sustentam da separação do lixo, o que proporcionou o descarte da biomassa "biogás" obtida por meio dos lixões públicos, embora tal produto possa vir a se tornar mais atrativo futuramente, para geração de energia.

O uso do farelo de polpa de laranja como fonte de energia é dificultado pela baixa disponibilidade, que decorre da alta demanda e de sua utilização pelo segmento de ração, já consolidado no mercado, e não por sua escassez natural. Além disso, seu potencial nutricional é elevado, razão de seu alto 
valor agregado. Apesar dessas informações, na VCP de Luiz Antônio, uma das empresas contatadas durante essa pesquisa, ao queimar um lote dessa biomassa em seus fornos para fins de teste, observaram-se emissão de gases poluentes e presença de corrosão dos equipamentos, fatores responsáveis pelo baixo entusiasmo com sua utilização.

Assim como o bagaço de laranja, as embalagens Tetra-Pak possuem alto valor agregado, pois podem ser utilizadas em diversos fins, principalmente na "reciclagem", da qual se obtém matéria-prima para fabricação de certos tipos de papelão. Nesse contexto, muitas indústrias de pequeno porte as utilizam na fabricação de vassouras, telhas, artefatos de escritório, dentre outros. Vale frisar que, além desses fatores, a própria empresa Tetra-Pak não recomenda o uso de seus produtos para queima ou incineração, devido a questões ambientais.

O óleo de fritura apresentou-se atrativa opção de geração energética, no entanto, em visitas realizadas a restaurantes industriais constatou-se que sua oferta é muito escassa, além de ser utilizada em indústrias de cosméticos, sabão e massa para vidros. Se, apesar desses fatores pessimistas, a opção fosse pela utilização dessa biomassa, seria recomendada uma parceria com grandes consumidores, como, por exemplo, a UFRJ e o McDonald's, que desenvolvem, conjuntamente, projetos voltados à viabilização do biodiesel em veículos de transporte urbano, e também a USP de Ribeirão Preto, que atualmente desenvolve pesquisas direcionadas a esse setor.

Finalmente, o gás natural apresenta-se como última alternativa de biomassa analisada e caracterizada como portadora de grande potencial para geração de energia, porém não indicada para queima em caldeira. Tal classificação é conferida devido ao seu elevado preço para consumo, embora o Governo Federal esteja incentivando atualmente sua utilização, no intuito de que venha a se tornar grande fonte de energia no futuro. Soma-se a isso a descoberta de novas e grandes reservas de gás pela Petrobras. Pesquisas e visitas a diversas empresas, durante esse trabalho, permitiram observar a utilização dessa biomassa por empresas da região 
do Estado de São Paulo, o que indica tendência de crescimento de sua utilização, apesar do alto investimento necessário em equipamentos.

$\mathrm{Na}$ fase seguinte focou-se apenas nas biomassas que obtiveram a melhor classificação, ou seja, resíduos de madeira e bagaço de cana-de-açúcar.

\subsection{Avaliação técnico-econômica}

Durante a terceira fase foi realizada uma busca exaustiva das localizações de todas as potenciais fontes das biomassas na área de influência, abrangendo serrarias, indústrias moveleiras e usinas de açúcar e álcool na área de influência. De posse desses dados, o contato direto via telefone foi realizado, a fim de confirmar o valor praticado no mercado tanto para venda como para frete dos produtos até a indústria; a localização/endereço da empresa; e a quantidade de biomassa disponível.

Para a biomassa "bagaço de cana-de-açúcar" foram contatadas 83 usinas de açúcar e álcool, 57 localizadas no Estado de São Paulo (70\%) e 26, no Estado do Paraná (30\%).

Já para a biomassa "resíduos de madeira" foram contatadas 500 serrarias e madeireiras, todas localizadas no Estado de São Paulo. Desse total, cerca de $60 \%$ respondeu pelo menos parte das informações solicitadas. Desse montante, $40 \%$ (24\% do total) se mostrou minimamente viável, ou seja, produzia pelo menos 12 toneladas por semana, o que seria suficiente para encher um "truck". Em números, 48 serrarias e madeireiras poderiam fornecer serragem ou cavaco para a indústria.

\subsection{Elaboração de instrumento de atualização}

A quarta fase foi realizada em paralelo com a terceira. Toda estrutura de modelagem matemática sobre otimização para captação de biomassa, levando em consideração o custo do material e frete, foi realizada de 
maneira que se disponibilizasse ferramenta gerencial para apoiar a tomada de decisão pela indústria, durante a aquisição das biomassas. Nesse sentido, os produtos dessa última fase foram mapeamento da oferta de biomassa, planilha de controle de entrada e saída de fornecedores das biomassas e dados sobre distâncias, modais de transporte e informações comerciais. No processamento do modelo de otimização especificado utilizou-se o "solver" do Microsoft Excel, como ferramenta de programação linear.

A ferramenta foi aplicada para as biomassas "resíduos de madeira" (serrragem e cavaco) e "bagaço de cana-de-açúcar", denominada "Biomática".

Com o cadastro de todos os fornecedores de resíduos de madeira e bagaço de cana-de-açúcar, na planilha eles foram classificados de acordo com o custo de aquisição da biomassa e frete relacionado com movimentação daquela biomassa. Dessa forma, a empresa pôde visualizar quais eram os fornecedores, onde estavam localizados, qual a distância até a indústria, qual o preço a ser pago, separado por frete, produto e potencial, e margem de negociação para aquisição das biomassas. Todos esses valores foram também comparados com os valores pertinentes do coque de petróleo.

\section{Discussão dos resultados}

Os resultados obtidos no mercado específico de cada biomassa estão nos Quadros 8 e 9. A principal resposta obtida diz respeito à indicação dos mercados fornecedores de cada uma das biomassas selecionadas, $\mathrm{o}$ que, basicamente, se refletiu na distância máxima a ser percorrida, a partir da sede da empresa, para aquisição da biomassa específica. 
Quadro 8 - Resultados obtidos para o bagaço da cana-de-açúcar

\begin{tabular}{|l|l|}
\hline Preço do bagaço em SP & Preço do bagaço em PR \\
\hline US\$ 4,21/Gcal + frete & US\$ $1,73 / \mathrm{Gcal}+$ frete \\
\hline US $\$ 9,49 / \mathrm{t}+$ frete & US\$ 3,90/t + frete \\
\hline Preço médio do bagaço & Preço médio do coque (frete incluso) \\
\hline US\$ 3,45/Gcal + frete & US\$ 6,53/Gcal \\
\hline US\$ 7,79/t + frete & US\$ 52,22/t \\
\hline Custo médio total estimado do bagaço: \\
\hline Bagaço + frete: US\$ $11,04 /$ Gcal \\
\hline Distância média: $381 \mathrm{~km}$ \\
\hline Composição do custo: $70 \%$ frete, $30 \%$ bagaço \\
\hline
\end{tabular}

Fonte: Dados da pesquisa.

Quadro 9 - Resultados obtidos para resíduos de madeira

\begin{tabular}{|l|l|}
\hline Preço médio do cavaco em SP & Preço médio da serragem em SP \\
\hline US\$ $4,47 / \mathrm{Gcal}+$ frete & US\$ $3,26 / \mathrm{Gcal}+$ frete \\
\hline US\$ $13,41 / \mathrm{t}+$ frete & US $\$ 9,79 / \mathrm{t}+$ frete \\
\hline Preço médio da madeira & Preço médio do coque (frete incluso) \\
\hline US\$ $\$, 87 / \mathrm{Gcal}+$ frete & US $\$ 6,53 / \mathrm{Gcal}$ \\
\hline US\$ $11,60 / \mathrm{t}+$ frete & US\$ $52,22 / \mathrm{t}$ \\
\hline Custo médio total estimado: & \\
\hline Serragem + frete: US\$ 6,36/Gcal \\
\hline Cavaco + frete: US\$ 7,56/Gcal \\
\hline Distância média (cavaco + serragem): $192 \mathrm{~km}$ \\
\hline Composição do custo para serragem: $48 \%$ frete, $52 \%$ serragem \\
\hline Composição do custo para cavaco: $41 \%$ frete, $59 \%$ bagaço \\
\hline
\end{tabular}

Fonte: Dados da pesquisa.

Para obter a distância máxima necessária a ser percorrida para aquisição de determinada biomassa, tomou-se como referência o preço médio do coque de petróleo, com o frete incluso. Percebe-se que o frete impactou, significativamente, o preço final da biomassa, o que fez com que maior atenção fosse dada ao transporte.

Note-se que a distância indicada para o bagaço $(372 \mathrm{~km})$ foi maior que a observada para resíduos de madeira $(192 \mathrm{~km})$, devido ao fato de o custo do bagaço (por Gcal) ser menor que o de resíduos de madeira. Tal fato 
Lilian Maluf de Lima, Ana Maria Kefalás Oliveira, Paulo de Tarso Carletti Filho, Renata Cristina Ferrari \& José Vicente Caixeta Filho

acaba por implicar maior poder de barganha para o comprador, pois, a maiores distâncias, mais fornecedores foram potencializados.

Obtidas as informações de frete, equações que relacionassem o comportamento dos valores de frete com as distâncias percorridas puderam ser estimadas a partir da utilização de regressões lineares, com a utilização de regressão linear. Tais equações, que estão plotadas nas Figuras 2 e 3, foram utilizadas, como referência, na planilha de otimização "Biomática".

Destaca-se também que, segundo o mercado pesquisado, transportadoras que realizam a movimentação do bagaço fazem também, na sua maioria, transporte de cavaco e de serragem de madeira.
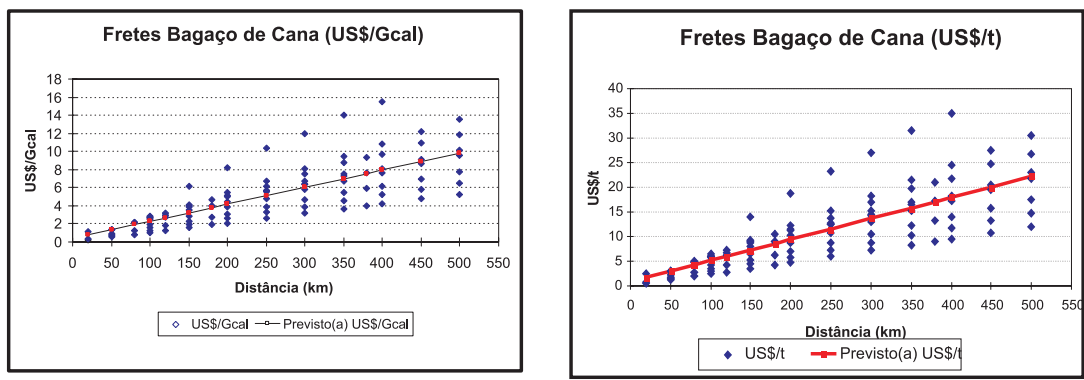

Figura 2 - Frete para bagaço de cana, em US\$/Gcal e em US\$/t, com base na distância percorrida.

Fonte: Dados da pesquisa.
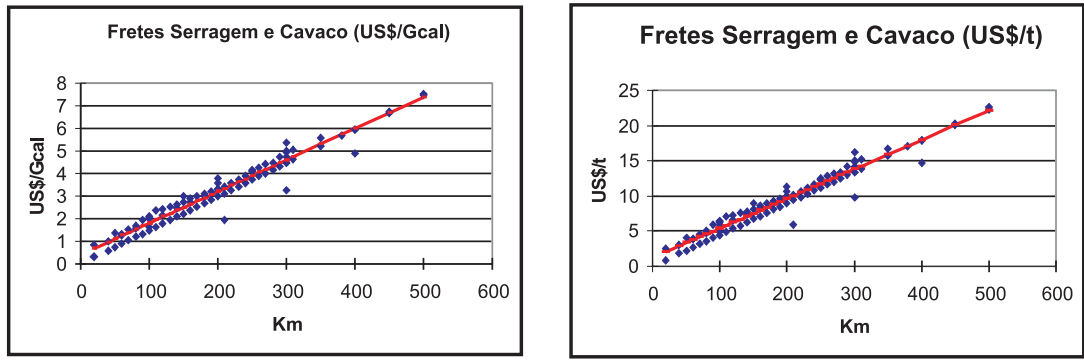

Figura 3 - Frete para serragem e cavaco de madeira, em US\$/Gcal e em US\$/t, com base na distância percorrida

Fonte: Dados da pesquisa. 


\section{Conclusões}

Este estudo mostrou que a substituição da atual fonte de energia se depara com limitações geográficas, principalmente relacionadas com distâncias a serem percorridas. O custo total da biomassa foi muito influenciado pelo frete relacionado. Da mesma forma, trata-se de um mercado extremamente dinâmico, no qual ainda não vigora determinado padrão de negociação.

Durante a realização dos estudos, algumas particularidades foram identificadas no mercado de resíduos de madeira e bagaço de cana-deaçúcar. Inicialmente, há a figura do "atravessador", denominação normalmente dada ao profissional que agrega produto para posterior venda no mercado. Esses profissionais não são facilmente encontrados no mercado, mas possuem maior poder de barganha, por ocasião da negociação com compradores de grandes volumes daquelas biomassas.

Para o bagaço da cana, a concorrência já está elevada, devido à cogeração adotada pelas usinas e indústrias de suco de laranja, que já se utilizam dessa biomassa há algum tempo. Além disso, haverá melhores perspectivas de eficiência de custo e de garantia de fornecimento do bagaço, se forem fechados contratos com algumas usinas e, ou, transportadoras antes do início da safra, pois trata-se de um produto sazonal.

O transportador também poderá tornar-se um intermediário no processo de aquisição do bagaço, tendo em vista a informalidade do mercado e os contatos que elas possuem. É interessante cadastrar a empresa que demanda bagaço nas usinas que ofertam, mesmo as que fazem cogeração, uma vez que há sobras, e a sazonalidade do uso pode implicar oferta em períodos distintos durante a safra da cana.

Para o mercado de resíduos de madeira haverá melhores perspectivas de eficiência de custo e de garantia de fornecimento dos resíduos, se forem fechados contratos com algumas serrarias, madeireiras, 
transportadoras ou intermediários antes do início do uso dessa biomassa. O transportador também poderá tornar-se um intermediário no processo de aquisição dos resíduos, pelos mesmos motivos do bagaço. Devido à não-organização desse mercado, ainda há espaço para busca de novos fornecedores potenciais, assim como há que se ter cuidados adicionais para evitar a aquisição de cargas adulteradas.

Por fim, constatou-se que, se ainda há oferta suficiente das biomassas "bagaço de cana-de-açúcar" e "resíduos de madeira" no mercado, há claras oportunidades de negócios para empresas especializadas no fornecimento de biomassas para indústrias, dado o ainda incipiente grau de profissionalização dos fornecedores e intermediários envolvidos nesse mercado.

\section{Referências}

BALLOU, R.H. Gerenciamento da cadeia de suprimentos: planejamento, organização e logística empresarial. Porto Alegre: Bookman, 2001.532p.

GLOSSÁRIO. http://www.energiasrenovaveis.com/html/canais/ glossario.htm (10 Fev. 2003)

BASTIANONI, S.; MARCHETTINI, N. Ethanol production from biomass: analysis of process efficiency and sustainability. Biomass \& Bioenergy, v.11, n.5, p.411-418, 1996.

BALANÇO ENERGÉTICO NACIONAL (BEN) em http:// www.mme.gov.br (12 Fev. 2003).

LOEFSTED, R.E. The use of biomass energy in a regional context: the case of Vaxjo Energi, Sweden. Biomass \& Bioenergy, v.11, n.1, p.3342, 1996. 
SOKHANSANJ, S.; TURHOLLOW, A.; CUSHMAN, J.; CUNDIFF, $\mathrm{J}$. Engineering aspects of collecting corn stover for bioenergy. Biomass \& Bioenergy, v.23, p.347-355, 2002.

Abstract: This study, conducted along the year 2003, was held in the environment of a cement company plant located in the São Paulo State. That industry has used carbon black as predominant energetic source which besides resulting a huge emission of gases $\left(\mathrm{CO}\right.$ and $\left.\mathrm{CO}_{2}\right)$ into the atmosphere, has been more expensive than some other alternatives of biomass sources. Taking into consideration the location of that plant, there was a large supply of available biomass to be used as alternative fuel for industrial ovens. Several biomasses were analyzed and it was concluded that the sugar cane bagasse and residues of wood (sawdust and woodchips) were the most appropriate alternatives to such an industry.

Keywords: biomass, energy, transport e optimization. 